\section{Case Reports in Neurology}

\title{
Mechanical Thrombectomy for Life-Threatening Cerebral Venous Thrombosis: A Case Report
}

\author{
Kar Foo Lau ${ }^{a, c}$ Tsun-Haw Toh ${ }^{a}$ Khairul Azmi Abdul Kadir \\ Mei-Ling Sharon Tai ${ }^{a}$ Kay Sin Tan ${ }^{a}$ \\ aDivision of Neurology, Department of Medicine, Faculty of Medicine University Malaya, \\ Kuala Lumpur, Malaysia; ${ }^{b}$ Department of Radiology, Faculty of Medicine University \\ Malaya, Kuala Lumpur, Malaysia; 'Faculty of Medicine and Health Sciences, Universiti \\ Tunku Abdul Rahman, Kajang, Malaysia
}

\section{Keywords}

Cerebral venous sinus thrombosis · Mechanical thrombectomy $\cdot$ Cerebral edema

\begin{abstract}
Cerebral venous thrombosis (CVT) is a rare cause of stroke worldwide with a wide range of clinical presentations. Anticoagulation therapy has been regarded as the first line of management of CVT to prevent the progression of thrombosis and to re-establish the venous flow. We present a case of severe CVT who did not respond to conventional anticoagulation therapy but responded well to mechanical thrombectomy (MT). This report highlights the features of CVT to consider for early MT.

(C) 2020 The Author(s)

Published by S. Karger AG, Basel
\end{abstract}

\section{Introduction}

Cerebral venous thrombosis (CVT) is a rare cause of stroke worldwide and it presents with a wide range of clinical presentations. Patients with CVT are generally treated with anticoagulation, while a small subset of patients were treated with mechanical thrombectomy (MT). We would like to present a case of life-threatening CVT who recovered well after MT.

\begin{tabular}{ll}
\hline & Lau Kar Foo \\
& Faculty of Medicine and Health Sciences \\
Universiti Tunku Abdul Rahman \\
Jalan Sungai Long, Bandar Sungai Long, Kajang 43000, Selangor (Malaysia) \\
edmondlkf@gmail.com
\end{tabular}




\section{Case Reports in Neurology}

Case Rep Neurol 2020;12:63-69

\begin{tabular}{l|l}
\hline DOI: 10.1159/000507343 & ๑ 2020 The Author(s). Published by S. Karger AG, Basel
\end{tabular} www.karger.com/crn

Lau et al.: Mechanical Thrombectomy for Life-Threatening Cerebral Venous Thrombosis

\section{Case Report}

A 32-year-old woman, 10 months postpartum with no previous medical illness, presented with a 1-day history of severe early morning headache and progressive deterioration of her conscious level while she was being rushed to the hospital. She had consumed herbal slimming pills and supplements for 1 month which were purchased online. We were unable to determine the exact content of the medication. There was no history of venous thrombosis, recurrent abortions or use of oral contraceptive pills. She was well prior to the onset of headache with no history of fever, seizure or double vision.

Upon arrival to the Accident and Emergency Department of a peripheral hospital, her Glasgow Coma Scale score was noted to be $4 / 15$ and she was intubated by the emergency physician for airway protection. She was transferred to our center, a tertiary level teaching hospital with comprehensive stroke care facilities for further management. On examination, her pupils were pinpoint bilaterally. A plain brain computed tomography (CT) showed mild cerebral edema with hyperdense lesion over the left transverse sinus. A post contrast CT showed filling defects in the dural sinuses involving the superior sagittal sinus, straight and left transverse sinuses (Fig. 1a).

She was given subcutaneous enoxaparin $90 \mathrm{mg}$ twice a day and was admitted to the intensive care unit for cerebral protection and close monitoring. Despite medical treatment, she did not show any signs of improvement and her serial scan showed worsening cerebral edema and subarachnoid hemorrhage (Fig. 1b). She underwent mechanical thrombectomy on the third day of admission. Post procedure venogram showed improved flow within the dural sinuses (Fig. 2). Her condition improved tremendously, and she was extubated on day seven. She had a residual left lower motor neuron facial nerve palsy and mild bilateral abducens nerve palsy. After 2 weeks of inpatient care, she was discharged home after adequate warfarinization. Her routine blood investigations, connective tissue disease screening, coagulation profile and anticardiolipin antibody were negative.

During her follow-up, she remained well with no neurological deficits. Her repeated scans showed residual hemorrhagic infarct changes at the left occipital lobe (Fig. 3) and some residual filling defects within the venous sinuses. She was maintained on warfarin on follow-up.

\section{Discussion}

CVT accounts for less than $1 \%$ of the stroke incidence worldwide with a high morbidity and mortality rate $[1,2]$. Multiple risk factors are associated with CVT. This includes transient risks such as pregnancy, oral contraception pills and infections. Permanent risks include antiphospholipid syndrome, blood disorders or malignancy [1,3]. The diagnosis of CVT is usually delayed or missed in view of a diverse range of presenting symptoms. Common presenting symptoms include those suggestive of raised intracranial pressure such as headache $75-$ $90 \%$ ), blurring of vision, altered mental status or seizures [2]. Other features may include focal neurological deficit which might suggest the location of the thrombus [4].

A plain brain CT remains as the first imaging modality for patients presenting with acute neurological deficits as it is fast and widely available. The classical signs that suggest CVT include intracerebral hemorrhages in about $30-40 \%$ of patients, ischemic lesion that crosses the arterial boundaries particularly with hemorrhagic component in proximity to a venous sinus, cerebral edema or hyperdensity of the occluded sinuses [4]. With advanced

\section{Karger'=}




\section{Case Reports in Neurology}

Case Rep Neurol 2020;12:63-69 DOI: $10.1159 / 000507343$

(c) 2020 The Author(s). Published by S. Karger AG, Basel www.karger.com/crn

Lau et al.: Mechanical Thrombectomy for Life-Threatening Cerebral Venous Thrombosis

neuroimaging, CT venography and MR venography are the preferred imaging modalities for CVT, comparable to digital subtraction angiography. CT venography has a sensitivity and specificity of $75-100 \%$, while MR venography is more accurate with a sensitivity of $93 \%$ in showing filling defects of the occluded veins or sinuses-Another pathognomonic sign that can be visualized is the empty delta signs for superior sagittal sinus thrombosis, but this can only be seen in $4-28 \%$ of patients [5].

Anticoagulant therapy either with low-molecular weight heparin or unfractionated heparin has been regarded as the first line of management of CVT to prevent the progression of thrombosis and to re-established the venous flow regardless of the presence of intracerebral hemorrhage $[1,3]$. The International Study on Cerebral Vein and Dural Sinus Thrombosis (ISCVT) reported that male gender, age $>37$ years old, comatose, those with mental status disorder, intracranial hemorrhage on admission, thrombosis of deep venous system, central venous system infection and malignancy have a poorer prognosis [6]. In this group of patients, endovascular intervention together with anticoagulant therapy has been recommended, supported by small case series and case reports [5].

There are many different approaches for MT including catheter thrombolysis, balloonassisted thrombectomy, stent retrievers and penumbra aspiration system with no reported randomized controlled trials to ascertain the superiority of the different endovascular interventions $[1,5]$. Our patient was treated with a combination of stent retriever and direct aspiration thrombectomy known as "Solumbra" technique. The clot over the transverse and sigmoid sinus was removed by aspiration using ACE 64 Penumbra Reperfusion catheter while the clot in the superior sagittal sinus was removed by using Solitare thrombectomy device with ACE 64 Penumbra Reperfusion catheter. Partial recanalization was achieved with improvement of venous drainage noted at the end of the procedure.

Based on the systematic review done by Ilyas et al. [1], the indications for endovascular treatment include failure of systemic anticoagulation, extensive clot burden, cerebral edema, elevated intracranial pressure, altered mental status and progressive worsening of neurological symptoms. Bushnaq et al. [2] proposed a prediction score of deterioration for patients with CVT, which includes number of sinuses involved, level of consciousness, platelet and sodium level, use of oral contraceptive pill, papilledema and seizure activity on presentation. A score of more than 5 (out of 10) predicted a $50 \%$ or more chance of deterioration, and hence these patients should be considered for early endovascular therapy. Our patient had a score of 6 based on this scoring system. This proposed scoring system, however, still requires further study and evaluation.

In conclusion, mechanical thrombectomy is a useful intervention in treating cerebral venous thrombosis, especially in comatose patients or those who do not improve despite anticoagulant treatment.

\section{Acknowledgement}

We would like to thank the medical and nursing staff in the University of Malaya Medical Centre's ICU (Intensive Care Unit) for their expertise in supporting this patient.

\section{Karger'"}




\section{Case Reports in Neurology}

\begin{tabular}{l|l}
\hline Case Rep Neurol 2020;12:63-69 \\
\hline DOI: 10.1159/000507343 & $\begin{array}{l}\text { @ 2020 The Author(s). Published by S. Karger AG, Basel } \\
\text { www.karger.com/crn }\end{array}$ \\
\hline
\end{tabular}

Lau et al.: Mechanical Thrombectomy for Life-Threatening Cerebral Venous Thrombosis

\section{Statement of Ethics}

For this case report, the patient gave written informed consent for the initiation of the various treatment modalities. This study complies with the guidelines and was conducted in accordance with the World Medical Association Declaration of Helsinki. The subject has given written informed consent to publish the case and related images.

\section{Conflict of Interest Statement}

The authors have no conflicts of interest to declare.

\section{Funding Sources}

None.

\section{Author Contributions}

K.F. Lau is the first and corresponding author. He wrote the first draft of the manuscript and coordinated the subsequent revisions and the final submission.

K.F. Lau and T.-H. Toh are advanced neurology trainees who looked after the patient clinically as part of the stroke team.

M.-L.S. Tai and K.S. Tan oversaw the management of the patient as consultants of the stroke team.

K.A. Abdul Kadir performed the interventional procedures described in the case.

All authors reviewed the manuscript critically for accuracy, content, and clarity.

\section{References}

1 Ilyas A, Chen CJ, Raper DM, Ding D, Buell T, Mastorakos P, et al. Endovascular mechanical thrombectomy for cerebral venous sinus thrombosis: a systematic review. J Neurointerv Surg. 2017 Nov;9(11):1086-92.

2 Bushnaq SA, Qeadan F, Thacker T, Abbas M, Carlson AP. High-Risk Features of Delayed Clinical Progression in Cerebral Venous Thrombosis: A Proposed Prediction Score for Early Intervention. Intervent Neurol. 2018 Oct;7(6):297-307.

3 Ferro JM, Bousser MG, Canhão P, Coutinho JM, Crassard I, Dentali F, et al.; European Stroke Organization. European Stroke Organization guideline for the diagnosis and treatment of cerebral venous thrombosis endorsed by the European Academy of Neurology. Eur J Neurol. 2017 Oct;24(10):1203-13.

4 Saposnik G, Barinagarrementeria F, Brown RD Jr, Bushnell CD, Cucchiara B, Cushman M, et al.; American Heart Association Stroke Council and the Council on Epidemiology and Prevention. Diagnosis and management of cerebral venous thrombosis: a statement for healthcare professionals from the American Heart Association/American Stroke Association. Stroke. 2011 Apr;42(4):1158-92.

5 Lee SK, Mokin M, Hetts SW, Fifi JT, Bousser MG, Fraser JF; Society of NeuroInterventional Surgery. Current endovascular strategies for cerebral venous thrombosis: report of the SNIS Standards and Guidelines Committee. J Neurointerv Surg. 2018 Aug;10(8):803-10.

6 Ferro JM, Canhão P, Stam J, Bousser MG, Barinagarrementeria F; ISCVT Investigators. Prognosis of cerebral vein and dural sinus thrombosis: results of the International Study on Cerebral Vein and Dural Sinus Thrombosis (ISCVT). Stroke. 2004 Mar;35(3):664-70. 
Case Reports in Neurology
Case Rep Neurol 2020;12:63-69

DOI: $10.1159 / 000507343$

(C) 2020 The Author(s). Published by S. Karger AG, Basel www.karger.com/crn

Lau et al.: Mechanical Thrombectomy for Life-Threatening Cerebral Venous Thrombosis
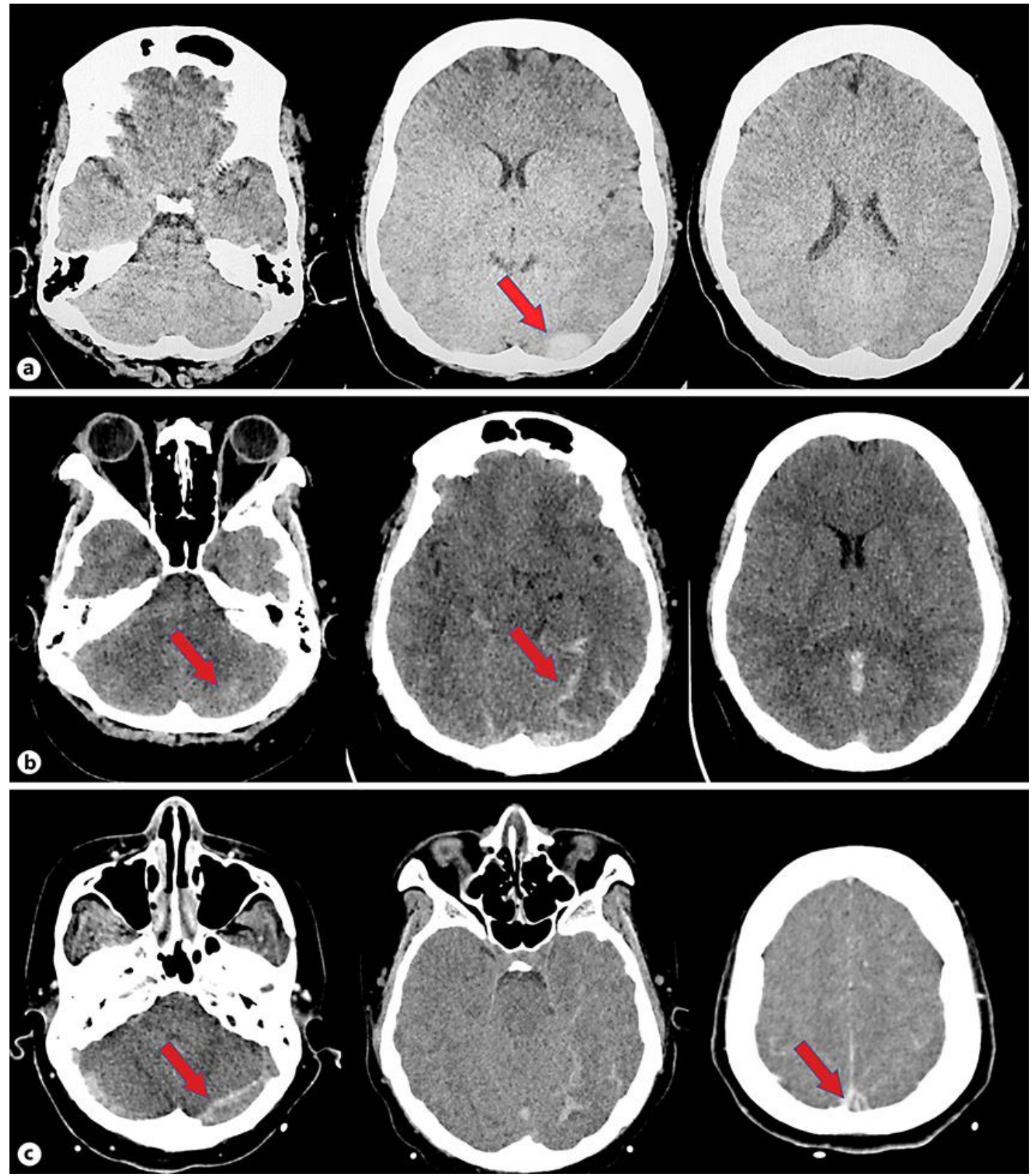

Fig. 1. a Initial plain CT of the brain showing the hyperdensity within the left transverse sinus with mild cerebral edema. $\mathbf{b}$ Repeated CT of the brain showing diffuse cerebral edema with subarachnoid bleed over the left occipital region. c Post contrast CT showing a filling defect in the dural sinuses and an empty delta sign, in keeping with diffuse cerebral dural sinus thrombosis. 
Case Reports in Neurology
Case Rep Neurol 2020;12:63-69

DOI: $10.1159 / 000507343$

(c) 2020 The Author(s). Published by S. Karger AG, Basel www.karger.com/crn

Lau et al.: Mechanical Thrombectomy for Life-Threatening Cerebral Venous Thrombosis
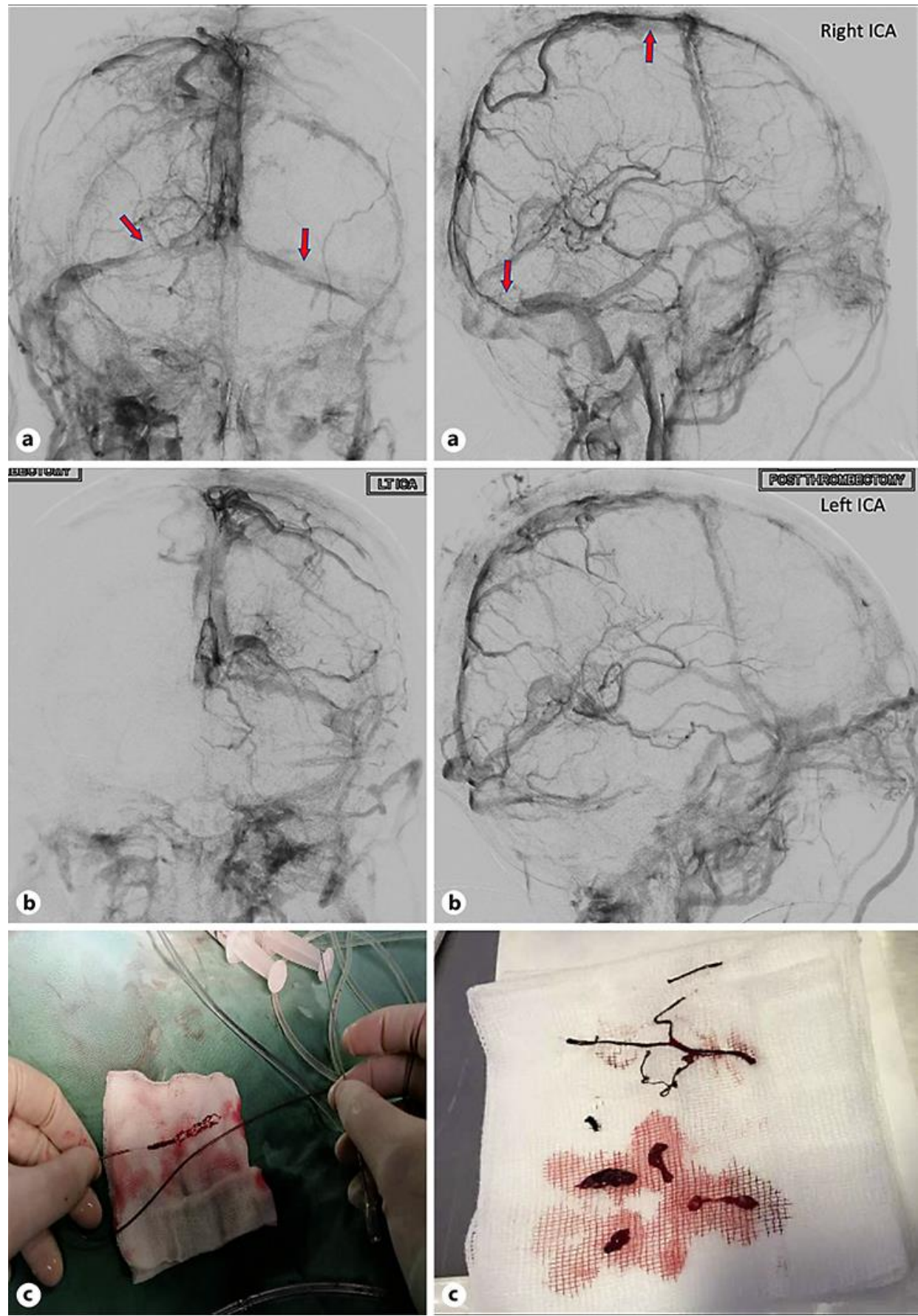

Fig. 2. a Pre-thrombectomy and clot suctions showing a thrombosed superior sagittal sinus, the medial portion of the right transverse sinus, the left transverse sinus, the left sigmoid sinus and left proximal jugular vein. b Post-thrombectomy and clot suction showing partial recanalization of the superior sagittal, left transverse and sigmoid sinus. c Blood clots that are successfully removed from thrombosed dural sinuses using stent retriever (Solitare) and suction catheter (Penumbra). 


\section{Case Reports in Neurology}

\begin{tabular}{l|l}
\hline Case Rep Neurol 2020;12:63-69 \\
\hline DOI: 10.1159/000507343 & $\begin{array}{l}\text { c 2020 The Author(s). Published by S. Karger AG, Basel } \\
\text { www.karger.com/crn }\end{array}$ \\
\hline
\end{tabular}
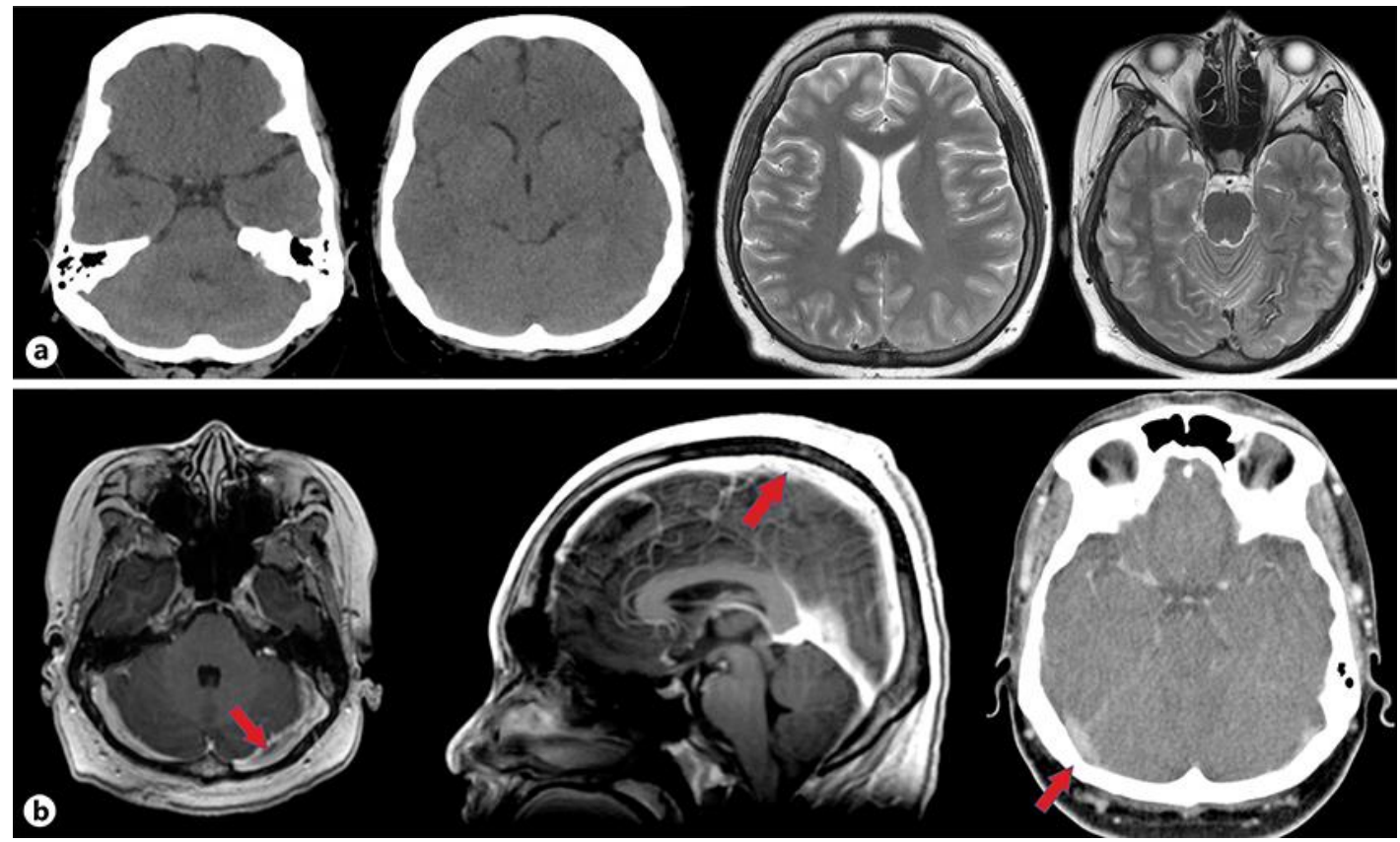

Fig. 3. a Follow-up CT and MRI showing reversal of cerebral edema with old hemorrhagic venous infarct at the left occipital lobe. $\mathbf{b}$ Recanalization of the dural sinuses seen on follow-up MR venography and contrast-enhanced MRI. 